\title{
Vertical Stacking of Copper Sulfide Nanoparticles and Molybdenum Sulfide Nanosheet for Enhanced Nonlinear Absorption
}

Ying Liang, ${ }^{\mathrm{a}, \mathrm{b}}$ Hui Li, ${ }^{\mathrm{c}, \mathrm{d}}$ Ruipeng Hou, ${ }^{\mathrm{a}}$ Jun Wang, ${ }^{\mathrm{c}}$ Kai Wang, ${ }^{\mathrm{e}}$ Mengke Ge, ${ }^{\mathrm{e}}$ Jun Luo, ${ }^{\mathrm{e}}$ Zhipeng Huang, ${ }^{* a}$ Chi Zhang ${ }^{* a}$

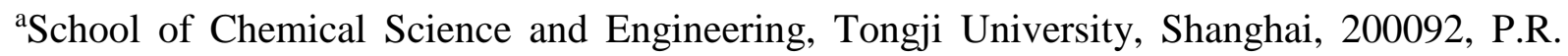
China.

${ }^{\mathrm{b}}$ School of Pharmacy, Shanghai University of Medicine and Health Sciences, Shanghai, 201318, P.R. Materials China

${ }^{\mathrm{c}}$ Key Laboratory of for High-Power Laser, Shanghai Institute of Optics and Fine Mechanics, Chinese Academy of Science, Shanghai, 201800, P.R. China

${ }^{\mathrm{d} U n i v e r s i t y ~ o f ~ C h i n e s e ~ A c a d e m y ~ o f ~ S c i e n c e s, ~ B e i j i n g, ~ 100049, ~ P . R . ~ C h i n a ~}$

${ }^{\mathrm{e}}$ Center for Electron Microscopy and Tianjin Key Lab of Advanced Functional Porous Materials, Institute for New Energy Materials and Low-Carbon Technologies, School of Materials Science and Engineering, Tianjin University of Technology, Tianjin, 300384, P.R., China

*To whom correspondence should be addressed:

*E-mail: zphuangh@ tongji.edu.cn (Zhipeng Huang)

*E-mail: chizhang@tongji.edu.cn (Chi Zhang) 
Table of contents

Part I. Supplementary Figures (S1-S8)

Part II. Supplementary Tables (S1-S3)

Part III. Discussion Section of calculation (I-IV) 


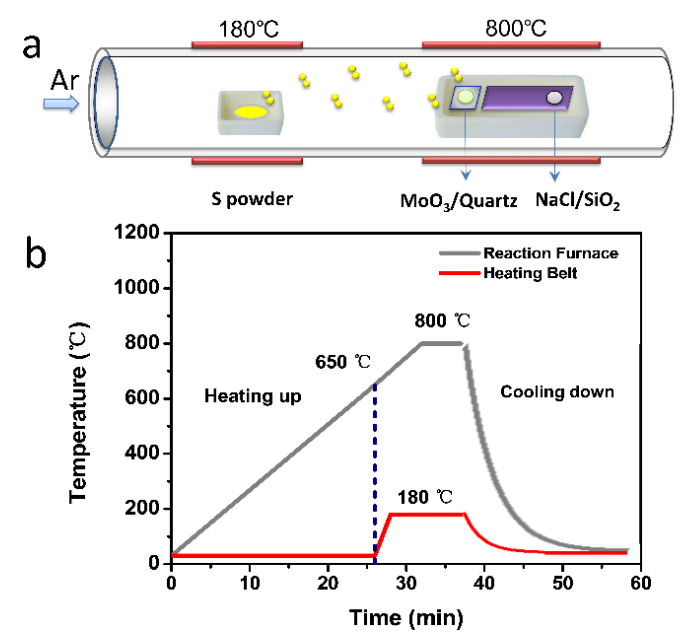

Figure S1. (a) A schematic illustration of the $\mathrm{MoS}_{2}$ ML CVD system. (b) The temperature programming process used for a typical growth of $\mathrm{MoS}_{2}$. 

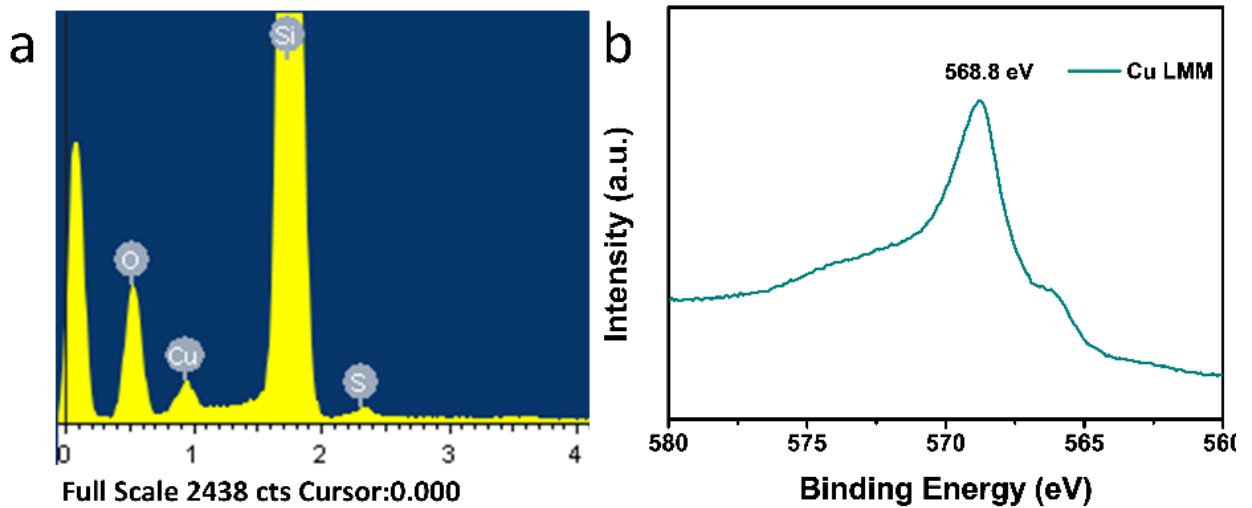

Figure S2. (a) The energy-dispersive X-ray spectroscopy (EDS) and (b) Auger Electron spectroscopy (AES) of $\mathrm{Cu}-\mathrm{LMM}$ of $\mathrm{MoS}_{2}-\mathrm{Cu}_{2-\mathrm{x}} \mathrm{S} \mathrm{HS}$. 


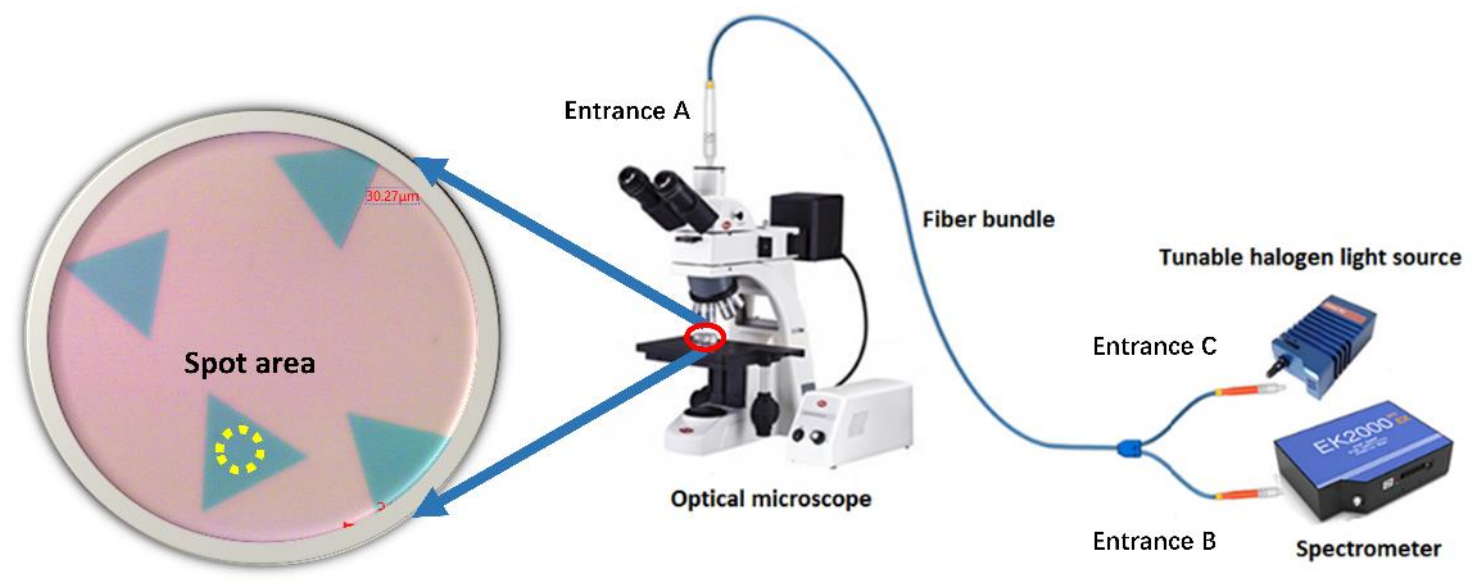

Figure S3. Schematic diagram of the experimental setup for performing micro-reflectance and transmittance spectroscopy on 2D materials.

In this work, we probe the local micro-reflectance of single layer $\mathrm{MoS}_{2}, \mathrm{MoS}_{2}-\mathrm{Cu}_{2-\mathrm{x}} \mathrm{S}$, and $\mathrm{Cu}_{2-\mathrm{x}} \mathrm{S}$ NP by modifying an optical microscope (Motic BA310Met-T). The experimental setup is similar to that reported by Ref 1 . Y shape optical fiber bundle was used to collect light and identify the signal spot site, with its Entrance A placed at the image plane of microscope, Entrance B (core fiber, $200 \mu \mathrm{m}$ diameter) connected to fiber optical spectrometer, and Entrance $\mathrm{C}$ (eight fibers surrounding the core, $\sim 40 \mu \mathrm{m}$ diameter) connected to a halogen light source. The core fiber introduces the light reflected by sample into optical fiber spectrometer.

Figure S3 shows the experimental setup used for the hyperspectral imaging. The images of eight surrounding fibers (yellow dots in Figure S3) on the image plane helps us to identify the signal spot site of optical fiber spectroscopy (the region surrounded by yellow dots in Figure S3). The light in surrounding fiber was turned off before the measurement of spectrum. Therefore, the core fiber can only collect the light coming from a defined region of the sample. 

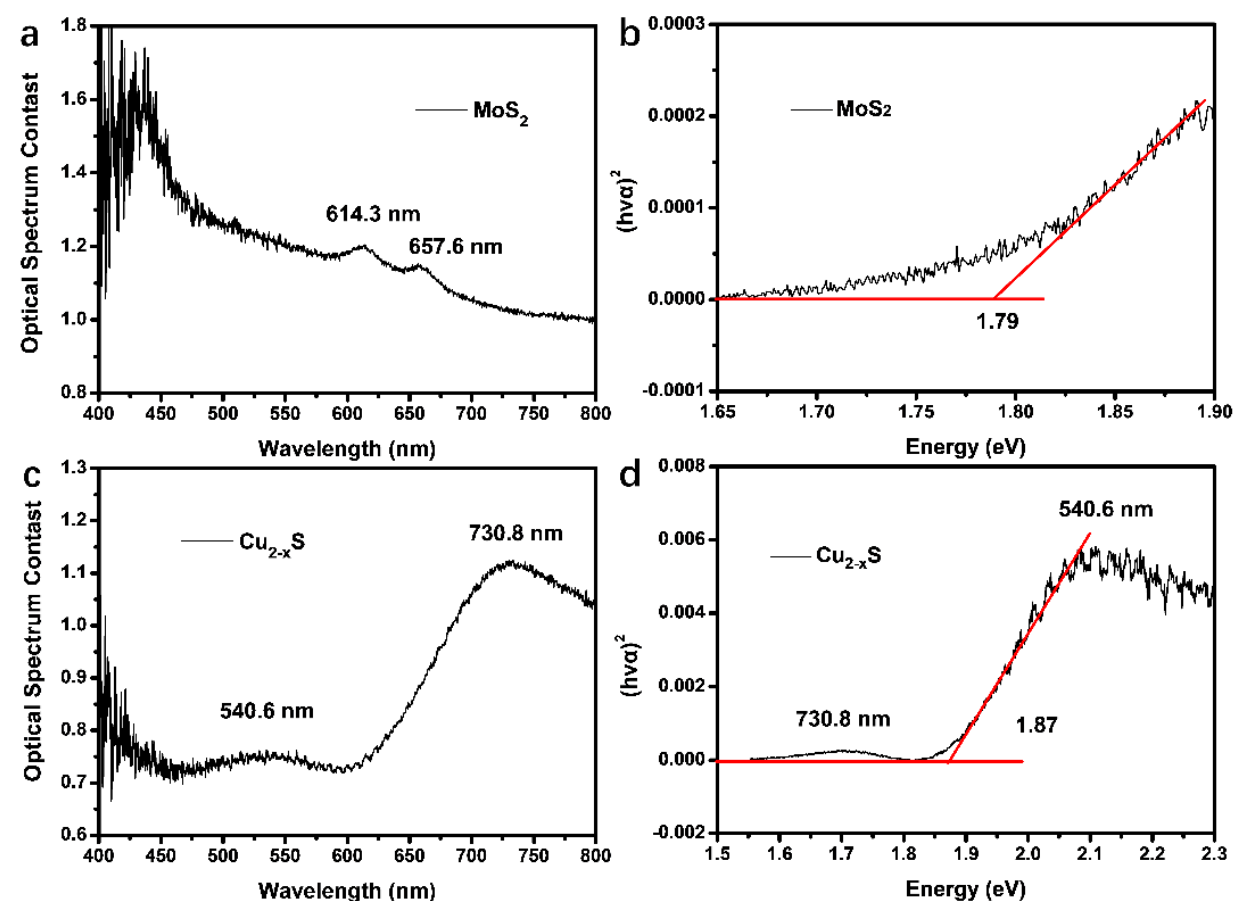

Figure S4. The optical spectrum contrast $\mathrm{R} / \mathrm{R}_{0}$ (a and c) and energy band gap (b and d) of $\mathrm{MoS}_{2}$ $\mathrm{ML}$ and $\mathrm{Cu}_{2-\mathrm{x}} \mathrm{S} \mathrm{NP}$. 


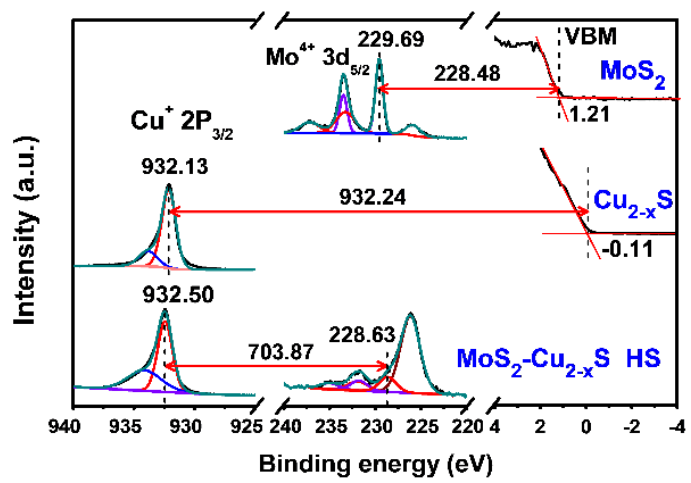

Figure S5. The XPS spectra for the isolated $\mathrm{MoS}_{2} \mathrm{ML}, \mathrm{Cu}_{2-\mathrm{x}} \mathrm{S}$ NP and $\mathrm{MoS}_{2}-\mathrm{Cu}_{2-\mathrm{x}} \mathrm{S}$ HS. All numbers have the unit of electron volt. 


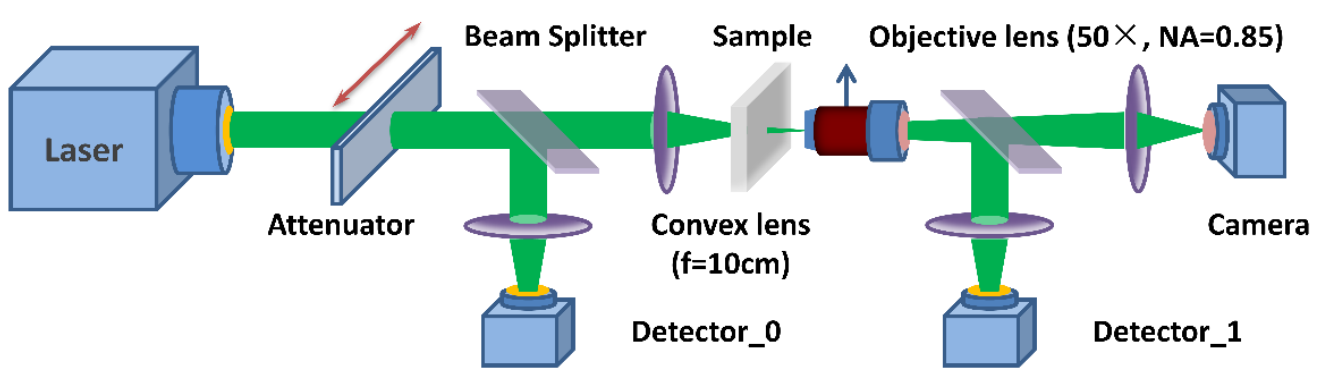

Figure S6. Schematic diagram of the $\mu$-I-scan system used for the nonlinear transmission/absorption experiment. 


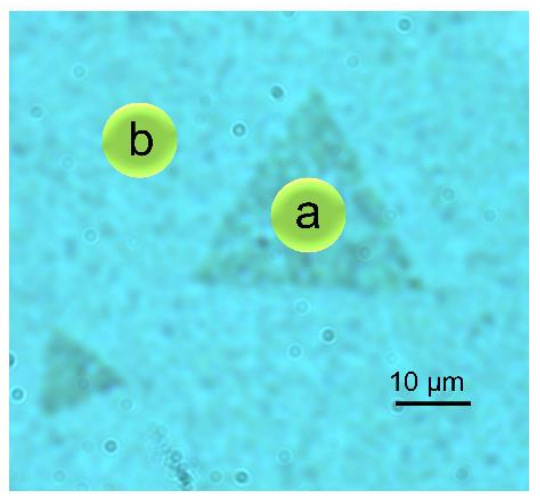

Figure S7. OM of (a) $\mathrm{MoS}_{2}-\mathrm{Cu}_{2-\mathrm{x}} \mathrm{S}$ HS and (b) $\mathrm{Cu}_{2-\mathrm{x}} \mathrm{S}$ NP on bare quartz substrate for the NLO measurements. 

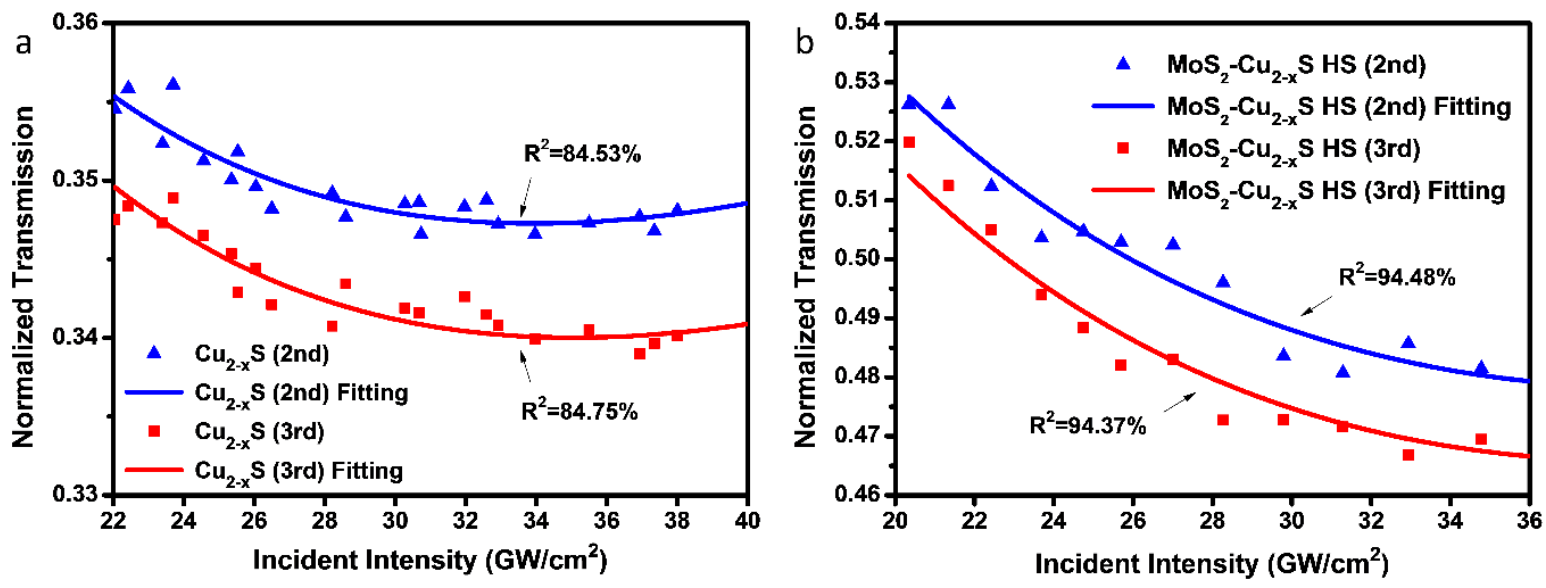

Figure S8. Transmittance versus incident pulse peak irradiance for (a) $\mathrm{Cu}_{2-\mathrm{x}} \mathrm{S} \mathrm{NP}$, and (b) $\mathrm{MoS}_{2^{-}}$ $\mathrm{Cu}_{2-\mathrm{x}} \mathrm{S} \mathrm{HS}$. 
Table S1: The number of $\mathrm{Cu}_{2-\mathrm{x}} \mathrm{S}(\mathrm{C})$ with different shapes.

\begin{tabular}{|c|c|c|c|c|}
\hline Regions & Triangles & Hexagons & Other shapes & Ratio of triangle and hexagon \\
\hline $\mathbf{0} \mathbf{~ m m - 1 0 ~} \mathbf{m m}$ & 50 & 18 & 13 & $84 \%$ \\
\hline $\mathbf{1 1} \mathbf{~ m m - 2 0 ~} \mathbf{~ m m}$ & 48 & 12 & 15 & $80 \%$ \\
\hline
\end{tabular}


Table S2. XPS and EDS microanalysis of $\mathrm{MoS}_{2}-\mathrm{Cu}_{2-\mathrm{x}} \mathrm{S} \mathrm{HS}$.

\begin{tabular}{|c|c|c|c|c|}
\hline \multicolumn{5}{|c|}{ MoS $_{2}-\mathrm{Cu}_{2-} \mathrm{S}$ HS } \\
\hline Element & \multicolumn{3}{|c|}{ XPS } & \multicolumn{2}{c|}{ EDS } \\
\hline & Weight Conc (\%) & Atom Conc(\%) & Weight (\%) & Atom (\%) \\
\hline $\mathbf{S i}$ & NA & NA & 77.83 & 69.62 \\
\hline $\mathbf{O}$ & 11.23 & 22.69 & 18.12 & 28.45 \\
\hline $\mathbf{S}$ & 15.62 & 15.74 & 0.86 & 0.67 \\
\hline Mo & 60.45 & 30.74 & 3.19 & 1.26 \\
\hline $\mathbf{C l}$ & 0.64 & 0.22 & NA & NA \\
\hline $\mathbf{C}$ & 1.04 & 0.95 & NA & NA \\
\hline Total & 11.02 & 29.66 & NA & NA \\
\hline
\end{tabular}


Table S3. EDS microanalysis for $\mathrm{MoS}_{2}-\mathrm{Cu}_{2-\mathrm{x}} \mathrm{S}$ HS and $\mathrm{Cu}_{2-\mathrm{x}} \mathrm{S}$ NP.

\begin{tabular}{|c|c|c|c|c|}
\hline \multirow{2}{*}{ Element } & \multicolumn{2}{|c|}{ MoS $_{2}-\mathrm{Cu}_{2-x} \mathrm{~S} \mathrm{HS}$} & \multicolumn{2}{|c|}{$\mathrm{Cu}_{2-\mathrm{x}}$} \\
\hline & Weight (\%) & Atom (\%) & Weight (\%) & Atom (\%) \\
\hline O K & 18.12 & 28.45 & 17.48 & 27.77 \\
\hline Si K & 77.83 & 69.62 & 76.65 & 69.40 \\
\hline S K & 0.86 & 0.67 & 1.23 & 0.97 \\
\hline Cu L & 3.19 & 1.26 & 4.64 & 1.86 \\
\hline Total & 100.00 & 100.00 & 100.00 & 100.00 \\
\hline
\end{tabular}




\section{Discussion Section I of calculation on band gap:}

The Tauc plot is used to determine the bandgap of semiconductor materials using the Tauc's relation, generally, for direct allowed transition as:

$$
\alpha h v=\mathrm{A}\left(\mathrm{h} v-\mathrm{Eg}_{\mathrm{g}}\right)^{1 / 2}
$$

where $\mathrm{A}$ is the constant having separate values for different transitions, Eg is the band gap, $\mathrm{h} v$ is the incident photon energy. ${ }^{2}$ The variation of $(\alpha h v)^{2}$ versus $h v$ is linear, which means that the mode of transition in this film is of a direct nature. ${ }^{3}$ 


\section{Discussion Section II of calculation on band alignments:}

The core-level separation between the Mo $3 \mathrm{~d}_{5 / 2}$ and $\mathrm{Cu} 2 \mathrm{p}_{3 / 2}$ is determined to be 703.87 $\mathrm{eV}$ in the HS. To determine the valence band offset $\left(\Delta \mathrm{E}_{\mathrm{v}}\right)$, the energy difference between corelevel and VBM is essential. With a least-square fit of the leading edge of the VBM spectra, the apparent VBM locations are determined to be $1.21 \mathrm{eV}$ for $\mathrm{MoS}_{2} \mathrm{ML}$ and $-0.11 \mathrm{eV}$ for $\mathrm{Cu}_{2-\mathrm{x}} \mathrm{S}$ NP. Therefore, the energy difference between Mo $3 \mathrm{~d}_{5 / 2}$ and the VBM of $\mathrm{MoS}_{2}$ is $228.48 \mathrm{eV}$, and that between $\mathrm{Cu} 2 \mathrm{p}_{3 / 2}$ and the $\mathrm{VBM}$ of $\mathrm{Cu}_{2-\mathrm{x}} \mathrm{S} \mathrm{NP}$ is be $932.24 \mathrm{eV}$. Assuming that the energy difference between the VBM and the core level remains unchanged after the formation of HS, the apparent $\Delta \mathrm{E}_{\mathrm{v}}$ for $\mathrm{MoS}_{2} \mathrm{ML}$ and $\mathrm{Cu}_{2-\mathrm{x}} \mathrm{S} \mathrm{NP}$ and in the stacked film $\mathrm{Cu}_{2-\mathrm{x}} \mathrm{S}$ NP on $\mathrm{MoS}_{2} \mathrm{ML}$ can be determined as: ${ }^{4}$

$$
\begin{aligned}
\Delta \boldsymbol{E}_{V} & =\left(E_{M o 3 d}^{M o}-E_{V B M}^{M o}\right)^{M o S_{2}}-\left(E_{C u 2 P}^{C u}-E_{V B M}^{C u}\right)^{C u_{2-x} S}-\left(E_{M o 3 d}^{M o}-E_{C u 2 P}^{C u}\right)^{M o S_{2}-C u_{2-x} S H S} \\
& =228.48-932.24+703.87=0.11 \mathrm{eV}
\end{aligned}
$$

and the conduction band offset $\left(\Delta \mathrm{E}_{\mathrm{c}}\right)$, and for the $\mathrm{MoS}_{2}-\mathrm{Cu}_{2-\mathrm{x}} \mathrm{S}$ HS was calculated using the following equation:

$$
\Delta \boldsymbol{E}_{\boldsymbol{C}}=E_{g}^{\mathrm{MoS}_{2}}-E_{g}^{C u_{2} S}+\Delta E_{v}=1.79-1.87+0.11=0.03 \mathrm{eV}
$$




\section{Discussion Section III of calculation on thickness:}

It is worth nothing that the thickness of $\mathrm{Cu}_{2-\mathrm{x}} \mathrm{S} \mathrm{NP}$ and $\mathrm{MoS}_{2}-\mathrm{Cu}_{2-\mathrm{x}} \mathrm{S}$ HS was estimated by the SEM-EDS analysis in Figure S7 and table S3. First of all, according to the quartz crystal density $\left(\rho_{\mathrm{SiO}_{2}}\right)$, quartz crystal thickness $\left(d_{\mathrm{SiO}_{2}}\right)$, quartz molar mass $\left(M_{\mathrm{SiO}_{2}}\right)$ and the atom relative percentage of Oxygen and Copper, the content of $\mathrm{O}$ element is used as the internal standard label to calculate the surface molar density of $\mathrm{Cu}_{2-\mathrm{x}} \mathrm{S}$ using the following equation:

$$
\begin{aligned}
& D_{\text {Surface }\left(\mathrm{MoS}_{2}-\mathrm{Cu}_{2-\chi} \mathrm{S} H \mathrm{HS}\right)}=\frac{\rho_{\mathrm{SiO}_{2}} \times d_{\mathrm{SiO}_{2}} \times P_{\text {atom }\left(\mathrm{Cu} \text { of } \mathrm{MoS}_{2}-\mathrm{Cu}_{2-\chi} \mathrm{SHS}\right)}}{M_{\mathrm{SiO}_{2}} \times P_{\text {atom }(O)}}=5.85 \times 10^{-8} \mathrm{~mol} / \mathrm{cm}^{2} \\
& D_{\text {Surface }\left(\mathrm{Cu}_{2-x} \mathrm{~S}\right)}=\frac{\rho_{\mathrm{SiO}_{2}} \times d_{\mathrm{SiO}_{2}} \times \mathrm{P}_{\text {atom }\left(\mathrm{Cu} \text { of } \mathrm{Cu}_{2-x} \mathrm{~S}\right)}}{M_{\mathrm{SiO}_{2}} \times P_{\text {atom }(\mathrm{O})}}=8.84 \times 10^{-8} \mathrm{~mol} / \mathrm{cm}^{2}
\end{aligned}
$$

Next, on the basis of molar mass of $\mathrm{Cu}_{2-\mathrm{x}} \mathrm{S}\left(M_{\mathrm{Cu}_{2-x} \mathrm{~S}}\right)$ and density of $\mathrm{Cu}_{2-\mathrm{x}} \mathrm{S}\left(\rho_{\mathrm{Cu}_{2-\mathrm{x}} \mathrm{S}}\right)$, the thickness can be calculated by the following equation:

$$
\begin{aligned}
& d_{M_{2} S_{2}-C u_{2-x} S H S}=\frac{M_{C_{2-x} S} \times D_{\text {Surface }\left(M_{o S} S_{2}-C u_{2-x} S H S\right)}}{\rho_{C u_{2-\chi} S}}=16.7 \mathrm{~nm} \\
& d_{C u_{2-x} S}=\frac{M_{C u_{2-x} S} \times D_{\text {Surface }\left(C u_{2-x} S\right)}}{\rho_{C u_{2-x} S}}=25.1 \mathrm{~nm}
\end{aligned}
$$




\section{Discussion Section IV of calculation on $\beta$ :}

The intensity of output beam $\left(\mathrm{I}_{\text {out }}\right)$ and that of incident laser $\left(\mathrm{I}_{\mathrm{in}}\right)$ are related by equation $(\mathrm{S}-8),{ }^{5-7}$

$$
\frac{\mathrm{d} I}{\mathrm{~d} z}=-\alpha I-\beta_{\mathrm{eff}}(I) I^{2}
$$

Where $I$ is the intensity of light, $z$ is the propagation distance in the sample, $\alpha$ is the linear absorption coefficient, and $\beta_{\text {eff }}(I)$ is the effective nonlinear absorption coefficient. The $\beta_{\text {eff }}(I)$ is correlated with nonlinear absorption coefficient $(\beta)$ and saturated intensity $\left(I_{\text {sat }}\right)$

via relation $\beta_{\mathrm{eff}}=\frac{\beta_{0}}{1+\frac{\mathrm{I}^{2}}{\mathrm{I}_{\text {sat }}^{2}}} .7$ The laser used in the I-Scan is Gaussian pulse beam. At each time (t) the intensity of incident beam $\left(I_{\text {in }}(t)\right)$ can be expressed as equation (S-9),

$$
I_{\text {in }}(t)=I_{0} \exp \left(-\frac{t^{2}}{\tau_{p}^{2}}\right)
$$

in which $\tau_{\mathrm{p}}$ is the pulse duration of laser, and $I_{0}$ is peak intensity of incident beam. The intensity of output beam $\left(I_{\text {out }}(t)\right)$ can be numerically solved from equation (S-8), and the transmission for a temporal Gaussian pulse can be computed by equation (S-10) 5,6

$$
T=\frac{\int_{-\infty}^{+\infty} I_{\text {out }}(t) \mathrm{d} t}{\int_{-\infty}^{+\infty} I_{\text {in }}(t) \mathrm{d} t}
$$

The I-Scan data can be fitted by resultant $\mathrm{T} \sim I_{0}$ relationship, and $\beta_{0}$ and $\mathrm{I}_{\text {sat }}$ can be determined. In numerically solving equation (S-8), $\alpha$ can be experimental derived from linear transmittance $\left(\mathrm{T}_{\mathrm{l}}\right)$ and effective thickness of samples $(d)$ via relation $\alpha=-\ln T_{\mathrm{l}} / d$. 


\section{References}

(1) Frisenda, R.; Niu, Y.; Gant, P.; Molina-Mendoza, A.; Schmidt, R.; Bratschitsch, R.; Liu, J.; Fu, L.; Dumcenco, D.; Kis, A.; Perez De Lara, D.; Castellanos-Gomez, A. Micro-Reflectance and Transmittance Spectroscopy: A Versatile and Powerful Tool to Characterize 2D Materials. J. Phys. D: Appl. Phys. 2017, 50. 074002.

(2) Saha, N.; Sarkar, A.; Ghosh, A. B.; Dutta, A. K.; Bhadu, G. R.; Paul, P.; Adhikary, B. Highly Active Spherical Amorphous MoS 2 : Facile Synthesis and Application in Photocatalytic Degradation of Rose Bengal Dye and Hydrogenation of Nitroarenes. RSC Adv. 2015, 5, 88848-88856.

(3) van Le, Q.; Nguyen, T. P.; Park, M.; Sohn, W.; Jang, H. W.; Kim, S. Y. Bottom-Up Synthesis of MeSx Nanodots for Optoelectronic Device Applications. Adv. Opt. Mater. 2016, 4, 1796-1804.

(4) Hudait, M. K.; Clavel, M.; Goley, P.; Jain, N.; Zhu, Y. Heterogeneous Integration of Epitaxial Ge on Si Using AlAs/GaAs Buffer Architecture: Suitability for Low-Power Fin Field-Effect Transistors. Sci. Rep. 2014, 4, 6964 .

(5) Gu, B.; Fan, Y.-X.; Wang, J.; Chen, J.; Ding, J.; Wang, H.-T.; Guo, B. Characterization of saturable absorbers using an open-aperture Gaussian-beam Z scan. Phys. Rev. A 2006, 73, 065803

(6) Gu, B.; Fan, Y.-X. Chen, J.; Wang, H.-T.; He, J.; Ji, W. Z-scan theory of two-photon absorption saturation and experimental evidence. J. Appl. Phys. 2007, 102, 083101

(7) Dong, N.; Li, Y.; Zhang, S.; McEvoy, N.; Gatensby, R.; Duesberg, G. S.; Wang, J. Saturation of Two-Photon Absorption in Layered Transition Metal Dichalcogenides: Experiment and Theory. ACS Photonics 2018, 5, 1558-1565. 